\title{
Recurrent Somatic Embryogenesis and Plantlet Regeneration in Psidium guajava L.
}

\author{
Anju Bajpai ${ }^{2}$, Shahina Kalim ${ }^{3}$, Ramesh Chandra ${ }^{2}$, Madhu Kamle ${ }^{1,2 *}$. \\ ${ }^{I}$ Ben-Gurion University of the Negev, The Jacob Blaustein Institute for Desert Research, Beer-Sheva, Beer-Sheva, \\ Israel. ${ }^{2}$ Central Institute for Subtropical Horticulture, Crop Improvement and Biotechnology, Lucknow, Uttar \\ Pradesh, India. ${ }^{3}$ Bundelkhand University, Jhansi, Department of Biochemistry Jhansi, UP, India.
}

\begin{abstract}
A simple and efficient protocol for recurrent somatic embryogenesis and plant regeneration is one of the prerequisites for genetic improvement of guava. An efficient reproducible regeneration somatic embryogenesis protocol was developed in four genotypes of Psidium guajava L. using immature zygotic embryo as starter explant. Somatic embryogenesis induction was obtained on MS basal medium supplemented with $2.0 \mathrm{mgL}^{-1}$ 2, 4-D, $400 \mathrm{mgL}^{-1} \mathrm{~L}_{\text {- }}$ glutamine, $6 \%$ sucrose and $500 \mathrm{mgL}^{-1}$ Malt extract. Following SE induction different developmental stages of somatic embryos (Globular, heart-shaped, torpedo, cotyledonary) was directly obtained and further recurrent embryogenesis also obtained upon prolonged incubation in induction media. Addition of polyethylene glycol (50 $\left.\mathrm{mgL}^{-1}\right)$ significantly improved the embryos maturation in MS supplemented with and 3\% sucrose. The regeneration in MS medium supplemented with BAP $\left(0.5 \mathrm{mgL}^{-1}\right)$, NAA $\left(0.2 \mathrm{mgL}^{-1}\right)$, casein hydrolysate $\left(100 \mathrm{mgL}^{-1}\right)$ and $3 \%$ sucrose. High plant regeneration frequency and intensity of somatic embryos (58.5\%) obtained. Plant maturation on MS medium supplemented with BAP $2.0 \mathrm{mgL}^{-1}$ with $2 \%$ sucrose. The rooted plants was successfully acclimatize in the greenhouse with a survival rate of $85 \%$. This somatic embryogenesis protocol developed would be helpful in establishment of genetically modified guava aimed at seedlessness, increased shelf life and wilt disease.
\end{abstract}

Key words: Somatic embryogenesis, zygotic embryo, recurrent, maturation, acclimatization, induction, regeneration

*Authors for correspondence: madhu.kamle18@gmail.com 


\section{INTRODUCTION}

Psidium guajava L. (Myrtaceae) generally known as guava 'the apple of tropics' consider one of the most important fruit of high nutraceutical value in international trade and domestic economy of several tropical and subtropical countries (Chandra et al., 2010; Kamle et al., 2013). Guava contains four times higher vitamin $\mathrm{C}$ than any other fruits. High concentration of pectin in guava plays noteworthy role in cholesterol drop and thus losses the cardiovascular diseases (Singh et al., 2005). Guava is low in calories and fats but carry several antioxidant poly-phenolic and flavonoid compounds that play a crucial role in prevention of many important diseases like cancer, aging, infections, etc. Scientific studies suggest that regular intake of vitamin $\mathrm{C}$ helps human body develop resistance against infectious agents and scavenge cancer (Yadava, 1994). Guava has a vast gene pool and genetically diverse in nature. In general, guava propagates through seeds but seedlings are variable in both plant and fruit characteristics due to heterozygous nature of crop (Saw et al., 1991). Conventional guava propagation employed through cutting, grafting, stooling or air layering met with limited success in development of disease resistant cultivars due to the narrow genetic variability present in the guava germplasm (Chandra et al., 2004). Therefore, the best alternative on the road to guava genetic improvement is to resort somatic embryogenesis that help in mass propagation of elite and new genotypes in shorter periods.

Somatic embryogenesis (SE) is a perfect confrontational system in which every somatic cells under special circumstances build up into embryos and passing through various developmental stages ultimately give rise to a complete plantlet formation (Arnold et al., 2002). SE is one form of asexual reproduction by which somatic cells, under suitable induction conditions, undergo a complete genome shift and embark into a new developmental pathway ending in the formation of asexual embryos morphologically identical to their zygotic counterparts (Zimmerman, 1993; Schmidt et al., 1997; Arnold et al., 2002; Feher et al., 2003). During this unique developmental process, cells have to dedifferentiate, activate cell division, and reprogram their physiology, metabolism, and gene expression patterns (Yang and Zhang, 2010). Thus, SE is an ideal demonstration of plant totipotency, which represents how a somatic cells contain the essential genetic draft for complete plant development without fertilization (Zimmerman, 1993). In SE, direct root and shoot induction occurs, thus the plantlet could be multiplied and acclimatize fast. 2, 4-D is a master regulator of somatic embryogenesis induction in an array of crops (Arnold et al., 2002; Van Winkle et al., 2003; Feng et al., 2009) and a stress-inducing herbicide which invokes embryogenic efficiency as an adaptation mechanism (Feher et al., 2003; Feher et al., 2005). The formation of an embryogenic cell is related to nuclear DNA methylation in the presence of 2, 4-D (Leljak- Levanic et al., 2004). Thus, the dynamic changes occurs in chromatin structure induced by DNA methylation under the influence of 2, 4-D lead to genomic reprogramming in somatic cells. This modification might affect hormone responsive genes required for acquisition of embryogenic competence. The somatic cells within a plant contain the genetic information necessary to form a complete and functional plant (Feher et al., 2003). Even though they are not exactly the same as zygotic embryos (Dodeman et al., 1997). There are several reports on regeneration of normal plants from somatic embryos in different species. In SE chances of the occurrence of chimera is less thus a more efficient way of regeneration of the transformed plants. Besides, plants in which somatic embryogenesis was obtained, secondary or recurrent embryogenesis was often present, a phenomenon in which new embryos emerges from somatic embryos (Raemarkers et al., 1995). Secondary somatic embryogenesis has many uses in biotechnology, such as the mass propagation of new plants, cryopreservation, genetic transformation and the induction of mutation (Litz and Gray, 1995; Raemarkers et al., 1995). Somatic embryogenesis in guava for biotechnological improvement programme has been reported by a various researchers (Akhtar et al., 2000; Chandra et al., 2004; Kosky et al. 2005; Rai et al., 2007; 2008; Saxena et al., 2007; Singh et al., 2007; Rai et al., 2009; Moura and Motoike, 2009; Akhtar, 2010; Kamle et al., 2013). Numerous problems encountered during the optimization of a high-efficiency protocol for induction of somatic embryogenesis from zygotic embryo explants of various cultivars of guava. Immature zygotic embryos utilized as the primary explants (Jaiswal and Litz, 1993) for the induction of somatic embryogenesis. The induction of somatic embryogenesis starting from mature and immature zygotic embryos has shown good results and efficiency in several plants of family Myrtaceae (Cruz et al., 1990; Canhoto and Cruz, 1996; Canhoto et al., 1999, Guerra et al., 1997). The advancement of efficient protocols for plant regeneration is one of the 
significant essentials for starting genetic transformation system in guava. In this research paper, we report an efficient recurrent regeneration via somatic embryogenesis in guava that can potentially pave the way in development of genetically modified guava with improved traits like seedlessness, increased shelf life and Fusarium wilt disease.

\section{MATERIAL AND METHODS}

\section{Preparation Of Explant}

Four commercial cultivars of guava (Allahabad Safeda, Lalit, Sardar (L-49) and Shweta) were sampled from the Orchard Block of Central Institute for Subtropical Horticulture, Lucknow, India. To ensure self-fertilization, un-opened flower buds were bagged and the 70 days post-anthesis immature fruits were collected. Immature fruits were brought to the laboratory and surface sterilized with water and then soaked in $\mathrm{HgCl}_{2}(0.1 \%)$ for 2-3 minutes containing one drop of Tween-20 for surface sterilization, washed thoroughly the fruits with sterile distilled water in order to remove traces of mercuric chloride. Flame sterilized the guava fruit using $90 \%$ ethanol for few seconds under laminar airflow. The sterilized fruit was bisected followed by the removal of immature seeds for zygotic embryos excision under aseptic condition. Immature zygotic embryos were chose as starter explants for inducing somatic embryogenesis. Dissection of zygotic embryos was isolated as described by Akhtar (2010).

\section{Induction Of Somatic Embryogenesis}

Excised immature zygotic embryos isolated from fruits of guava 70 (Days after Pollination) days was inoculated on petridish containing Murashigue and Skoog (1962) medium supplemented with 2, 4-D $\left(2 \mathrm{mgL}^{-1}\right)$, L-glutamine $\left(400 \mathrm{mgL}^{-1}\right)$, malt-extract $\left(500 \mathrm{mgL}^{-1}\right)$ and $6 \%$ sucrose. The $\mathrm{pH}$ of the medium adjusts to $5.8 \pm 0.2$. Each petridish contain ten zygotic embryos and incubate at $25 \pm 2{ }^{\circ} \mathrm{C}$ in dark for 4-6 weeks in induction medium. Globular embryos appeared after 6-8 weeks of inoculation, which formed bipolar-shape (Fig1). Somatic embryos subculture at every 4 weeks up to 12 weeks incubation in dark. Subculturing on induction medium devoid of hormone resulted in repetitive embryogenesis.

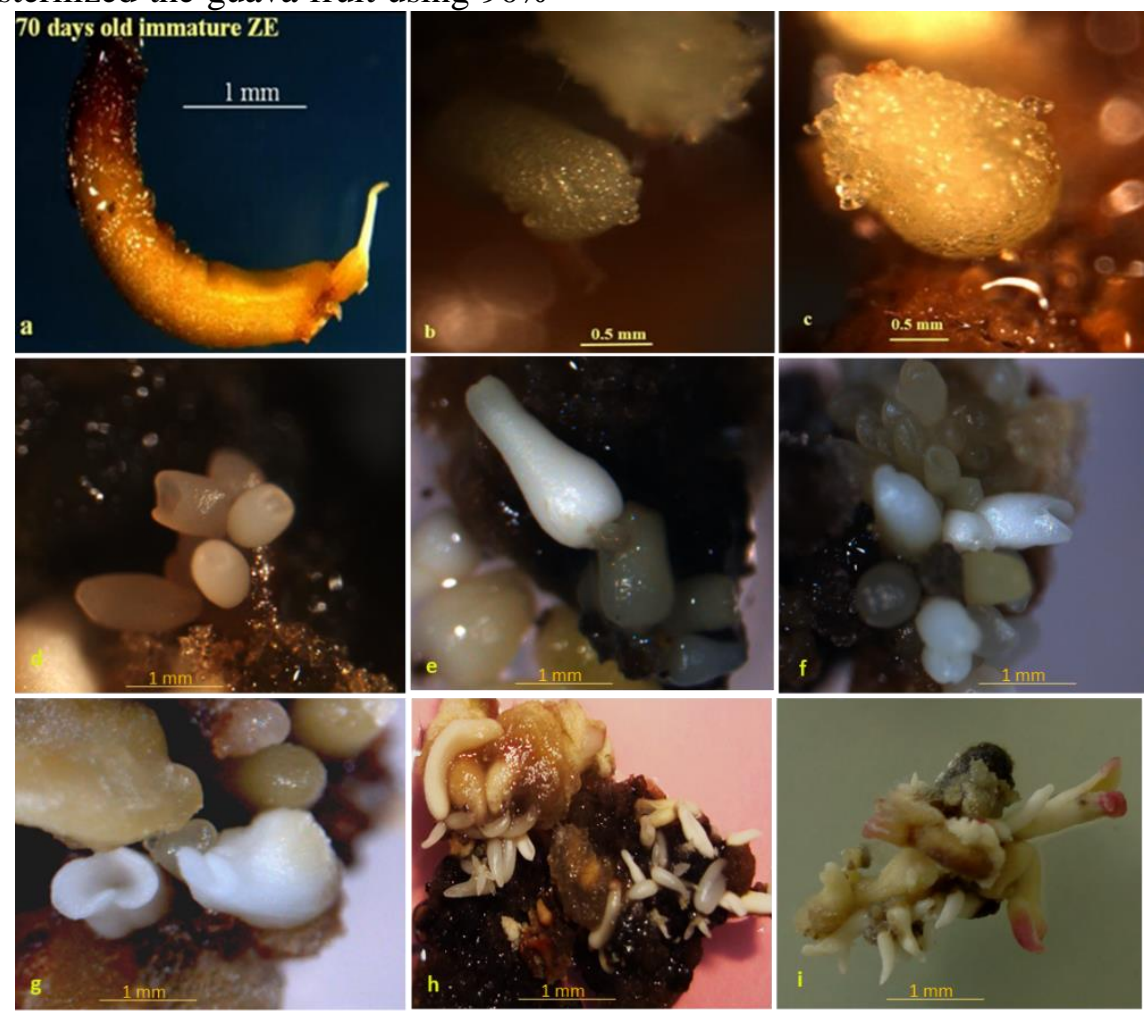

Figure 1 - Different developmental stages of somatic embryo induction in Psidium guajava L. a) 70 day zygotic embryo as explant source, b) Pre embryogenic mass of cells (PEMCs), c) protuberance of transparent PEMC in clump, d) globular \& heart shaped embryo, e) elongated embryo, f) torpedo-shaped embryos, g) cordiform embryo, h) embryo proliferation, i) recurrent embryogenesis. 


\section{Evaluation Of Somatic Embryogenesis}

1). Frequency of Embryogenesis (FE): The proportion of explants that showed at least one somatic embryo at any stage of development, out of the total number of explants inoculated in a particular treatment. FE (as a percentage) were calculate as follows:

Sum of the number of explants showing at least one Somatic embryo per treatment

$\mathrm{FE}(\%)=$ $\mathrm{x} 100$

Total number of explants inoculated per treatment

2). Intensity of Embryogenesis (IE): The mean number of somatic embryos produced per responsive explants in a particular treatment. The average number of somatic embryos produced per culture (ANEPC) represents IE and calculate as follows: embryos produced

Sum of total number of somatic

treatment in each explants in a particular

IE $($ ANEPC $)=$ $\mathrm{x} 100$

Total number of explants showing at least one Somatic embryo per treatment

\section{Histological Analysis}

Samples examine after 21 days of culture for the histo-chemical analysis of somatic embryos. The tissue samples were fix in FAA in ratio of 5: 5: 90 ( $5 \mathrm{ml} 40 \%$ formaldehyde: $5 \mathrm{ml}$ Glacial Acetic acid: 90 $\mathrm{ml} 70 \%$ ethanol). Ethanol dilution varies according to the soft tissue. After dehydration in an alcohol series (70\% for $60 \mathrm{~min}, 95 \%$ for $30 \mathrm{~min}$ and $100 \%$ for 15 min') the samples were subsequently embedded in paraffin wax at $58^{\circ} \mathrm{C}$. Serial $8 \mu \mathrm{m}$ thick sections were cut using a rotatory microtome (Leica, RM2125) using standard procedure and stained with deal field hematoxylin, fushin-astra blue combination and mounted in Canada balsam oil and photograph under a light microscope Leitz DMRB photomicroscope (Leica, Wetzler, Germany).

\section{Maturation, Plantlet Regeneration and Acclimatization}

For maturation, somatic embryos were placed in a MS basal medium containing PEG (50 mgL-1) and $3 \%$ sucrose.

Somatic embryos isolated from the clumps were placed onto the $1 / 2$ MS medium supplemented with BAP $\left(0.5 \mathrm{mgL}^{-1}\right)$ and NAA $\left(0.2 \mathrm{mgL}^{-1}\right)$, casein hydrolysate $\left(100 \mathrm{mgL}^{-1}\right)$ containing $3 \%$ sucrose for plantlet regeneration for 2-3 weeks. Later, plantlets transfer to $1 / 2 \mathrm{MS}$ medium supplemented with BAP $\left(2.0 \mathrm{mgL}^{-1}\right)$ and $3 \%$ sucrose for elongation and shoot proliferation. Four weeks after cultured into proliferation medium plantlets reached size of $5-8 \mathrm{~cm}$ along with developed root and shoot system, transfer plantlets to glass-bottles containing coco-peat moistened with $1 / 2 \mathrm{MS}$ plant salt mixture and covered with a plastic sheet for acclimatization. After a week made few perforations in the plastic sheet for aeration to plantlets and then shifted to green house at $25 \pm$ $2^{\circ} \mathrm{C}$. In greenhouse, transfer plants into pots filled with sand: soil: FYM $(1: 1: 1)$ and remove the polybags and let plants acclimatize completely too external environment. The plants grown in growth chambers $\left(24^{\circ} \mathrm{C} \pm 2{ }^{\circ} \mathrm{C}\right.$ and $16 \mathrm{~h}$ photoperiod with $80 \%$ relative humidity). Now, transfer plants into the field.

\section{Statistical Analyses}

All experiments was repeat at least three-times. All results were subject to two way analysis of variance (ANOVA) to detect significant variation at $\mathrm{CD} \pm$ 0.05 . All cultures were observed daily and changes in the zygotic embryo explants were noted after each week. Embryogenic responses were usually record 8-10 days after culture initiation. The efficacy of the various treatments calculated using two different embryogenic parameters as described by Akhtar (2010). Data were analyzed for two-way analysis of variance (SPSS version 16). Significance of difference $(\mathrm{P}<0.05)$ was detected.

\section{RESULTS}

In the present study, an efficient and highly reproducible system for Psidium guajava L. somatic embryogenesis was developed (Fig; 1a-i). Somatic embryogenesis induction: Somatic embryogenesis induction achieved using the immature zygotic embryo (70 DAP) as explant on MS medium, containing 2, 4-D (2.0 $\left.\mathrm{mgL}^{-1}\right)$ and L-glutamine (400 $\left.\mathrm{mgL}^{-1}\right)$ and $6 \%(\mathrm{w} / \mathrm{v})$ sucrose. Direct embryogenesis observed after 4 weeks post culture induction and later pre-embryogenic masses of cells (PEMC) developed directly from the immature zygotic embryo explants in all treatment except in the control after 4 weeks (Fig1). The addition of 2, 4-D $\left(2 \mathrm{mgL}^{-1}\right)$ with Lglutamine $\left(400 \mathrm{mgL}^{-1}\right)$ significantly increased formation of somatic embryos. Removal of auxin or decreasing concentration of auxin led to formation of repetitive embryogenesis (Chandra et al., 2004). After 6 weeks of incubation in induction, medium, granular 
and shiny masses of cellular embryos observed (Fig1). $\left(50 \mathrm{mgL}^{-1}\right)$ and $3 \%$ sucrose produced $83.64 \%$ This process continues in subsequent sub culturing cotyledonary embryos into maximum $74.28 \%$ leading to the successive formation of somatic matured embryos. For regeneration, transfer to $1 / 2$ embryos that emerged from the peripheral areas of the strength MS medium fortified with BAP $(0.5 \mathrm{mgL}$ callus mass after 8-weeks of culture incubation. $\left.{ }^{1}\right)$, NAA $\left(0.2 \mathrm{mgL}^{-1}\right)$ and casein hydrolysate $(100$ Various developmental stages observed of somatic $\mathrm{mgL}^{-1}$ ) containing 3\% sucrose for 2-3 weeks (Fig2). embryos first appeared as clusters of globular For conversion of somatic embryos into plantlets, the embryos, further into heart-shaped or cordiform shape somatic embryos now exposed to $16 / 8 \mathrm{hr}$. then torpedo-shaped and finally into cotyledonary photoperiod. This is the most critical stage for stage to form a complete plantlet. establishment of any successful regeneration protocol depends on conversion efficiency.

Maturation, Proliferation and Regeneration of Somatic embryos: Maturation is a key phase between embryo development and germination. To achieve maturation somatic embryos transferred to Percentage of conversion record after 3 weeks (Fig4). High plant regeneration frequency and intensity of somatic embryos (58.5\%) obtained.

MS medium supplemented with polyethylene glycol
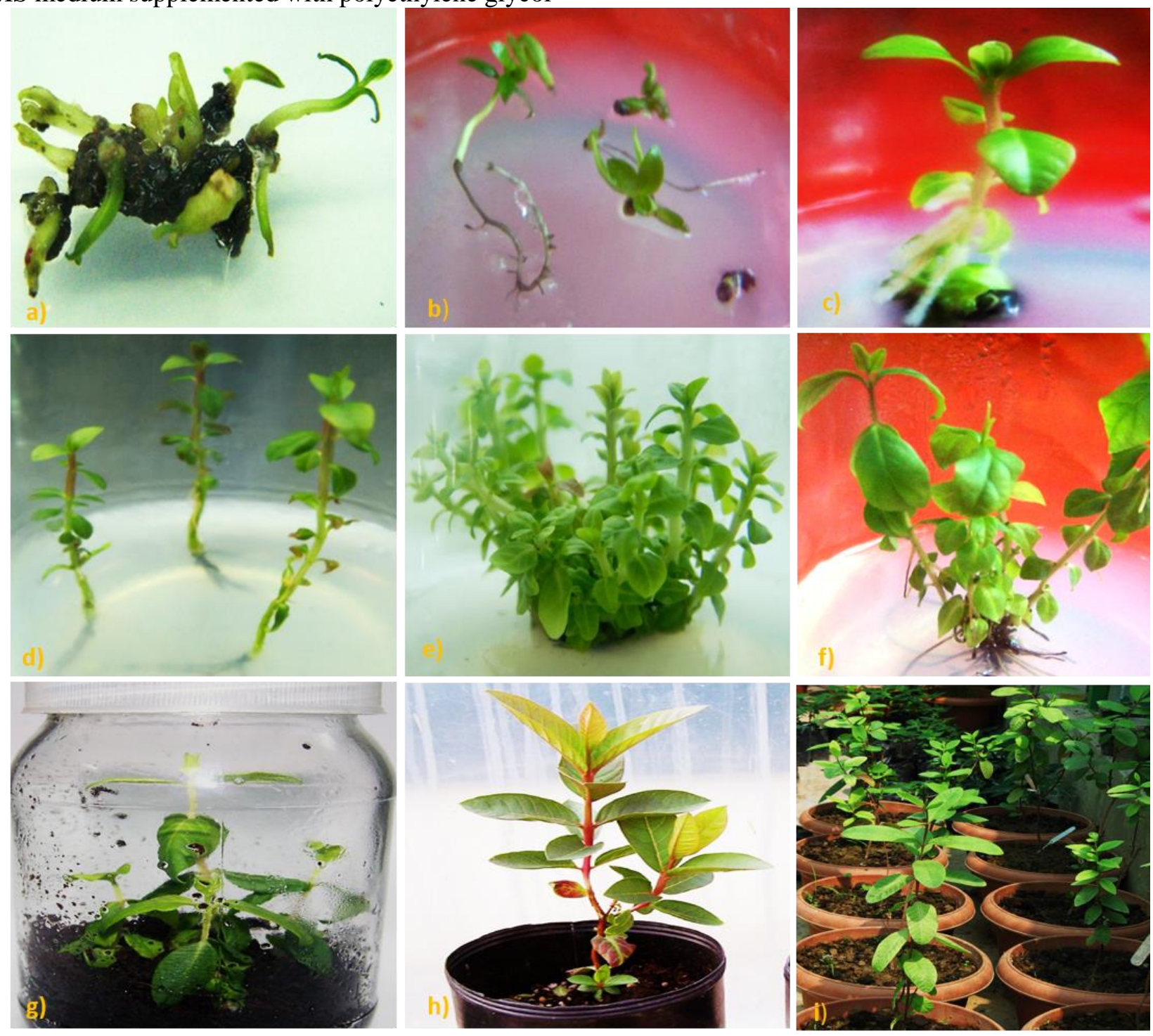

Figure 2 - a) Different stages of plantlet regeneration in guava through somatic embryogenesis pathway a) Maturation of somatic embryo b) plantlet germination c) rooting in plant d) elongation of plantlets e) shoot proliferation $f$ ) plant maturation g) plant in coco-peat h) hardening in poly-house i) Plants in soil-pots. 


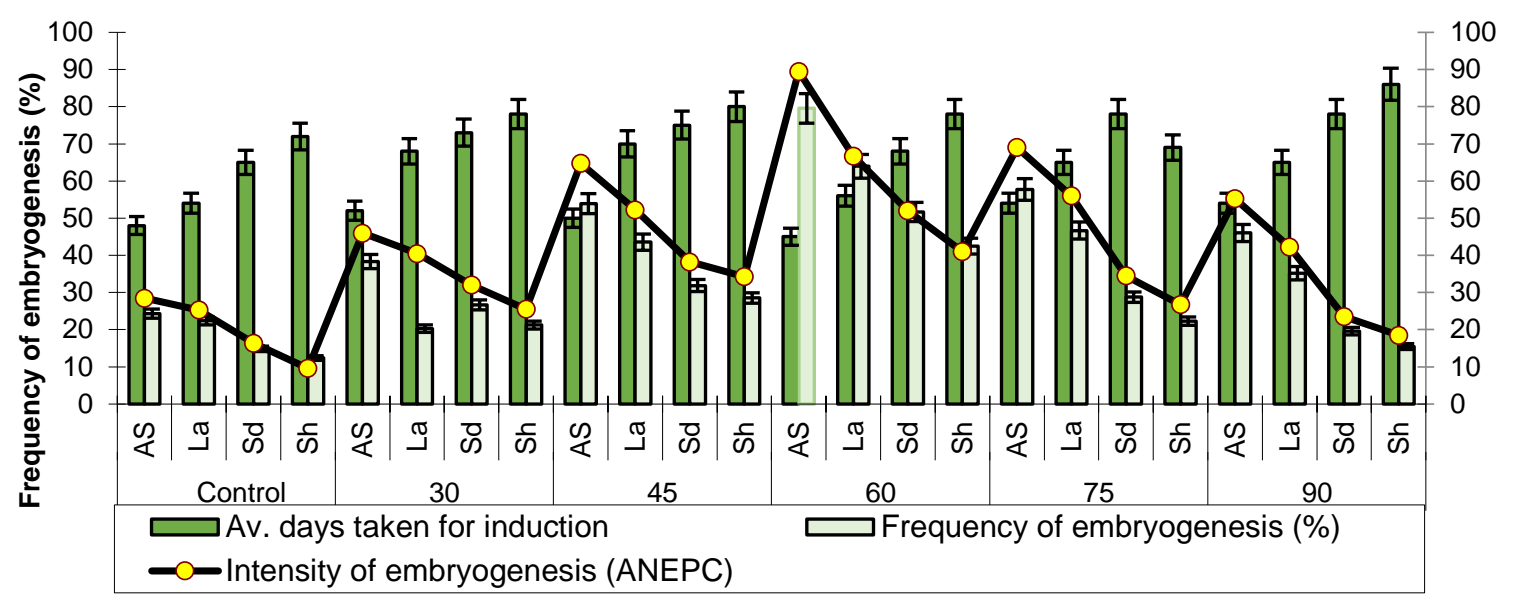

Interaction between Sucrose and Genotypes

Figure 3 - Effect of sucrose and its interactive effect on the four genotypes of guava. Represents maximum embryogenesis induction in terms of frequency and intensity with reference to the four genotypes

\section{Embryogenic Potential of Genotypes:}

Embryogenic potential of four guava genotypes viz. Allahabad Safeda, Lalit, Sardar (L-49) and Shweta was estimated on the maximum embryogenesis induction, maturation, plantlet regeneration was recorded in Allahabad Safeda which accounts for $32.5 \%$ plantlet regenerated followed by Lalit in which $23.3 \%$ regeneration was recorded. Least plantlet regeneration was recorded in Sardar (L-49) and Shweta which accounts for only $15.3 \%$. Comparative overall embryogenic potential we reported Allahabad Safeda as the most promising genotype of guava in terms of induction, maturation, proliferation via somatic embryogenesis through tissue culture as thus, could potentially use further in establishment of genetic transformation protocol.

\section{Effect of carrier substrate in acclimatization of Plantlets:}

Four different carrier substrates blend with bioagent Trichoderma harzianum was used viz., perlite and $T$. harzianum, Vermiculite $+T$. harzianum and cocopeat $+T$. harzianum and Sand + Soil + FYM for acclimatization of guava plantlets. Maximum survival of plants (data not shown) in substrate Cocopeat $+T$. harzianum $(85.40 \mathrm{~cm})$ was obtained and followed by Sand + Soil + FYM $(75.20 \mathrm{~cm})$. Later the genetic fidelity analysis of all plants was confirm using Molecular markers.

\section{DISCUSSION}

Advancement of efficient protocol for plant regeneration is crucial for establishment of genetic improvement. An orderly series of characteristic embryogenesis system have developed in guava under present investigation. Immature zygotic embryos have proved to be an efficient regenerative tissue for the many recalcitrant tropical fruit species. Zygotic embryos are made up of PEDC's (pre-embryogenic determined cells) in which, cells have the embryogenic competence and could easily induced to follow the embryogenic pathways (Sharp et al., 1980). Our results revealed that immature zygotic embryo (70 days post-anthesis) undergo rapid induction of somatic embryogenesis in terms of highest frequency and intensity over immature mesocarp. Our results are also in accordance with the results of Vilchez et al., 2000; Rai et al., 2007, Kosky et al., 2005 and Akhtar, 2010. Immature zygotic embryos have proved to be a potent regenerative tissue for the many recalcitrant tropical fruit species. 2, 4-D is consider as one of the main inductive factors for somatic embryogenesis (Ammirato, 1993) and is well established for many species (Dunstan et al., 1995) including several members of the Myrtaceae family (Canhoto et al., 1998). Among other Myrtaceae plants in which somatic embryogenesis has been induced Feijoa sellowiana (pineapple guava) and Myrtle communis where somatic embryos differentiate mostly from mature zygotic embryo (Canhoto and 
Cruz, 1996; Canhoto et al., 1999). Our results somatic embryos. Furthermore, combination of 2, 4revealed that $2 \mathrm{mgL}^{-1} 2,4-\mathrm{D}$ was the best $\mathrm{D}$ and glutamine induced high production of SEs concentration inducing somatic embryogenesis in (Chandra et al., 2004). Fortification of an organic Psidium guajava L. among all the four genotypes nitrogen form has a positive influence on somatic tested in terms of highest frequency and intensity of embryogenesis (Khlifi and Tremblay, 1995; Carman embryogenesis (Fig3). Conversely, Akhtar, (2010) et al., 1996; Garin et al., 2000; Robichaud et al., 2004; and Rai et al. (2007) specified that $1.0 \mathrm{mg} / \mathrm{l} \mathrm{2,} \mathrm{4-D} \mathrm{Chandra} \mathrm{et} \mathrm{al.,} \mathrm{2004;} \mathrm{Kosky} \mathrm{et} \mathrm{al.,} \mathrm{2005;} \mathrm{Biswas} \mathrm{et}$ concentration found best for somatic embryogenesis al., 2005; Rai et al., 2007; Zouine and Hadrami, 2007; in guava. The lower doses of 2, 4-D (1.0 mg/l) was Gerdakaneh et al., 2011). L-Glutamine had shown recommended to induce maximum embryogenesis improved somatic embryogenesis in both with increase in concentration of 2, 4-D (>1.0 mg/l) monocotyledons and dicotyledons (Dhir et al., 1991; was increased the frequency and intensity of somatic Yin et al., 1993; Ke et al., 1996; Vani and Reddy et embryo diminution. In case of guava (Psidium al., 1996; Srivastava and Chawla 2001). The addition guajava L.) genotypes exposure of 2, 4-D in of L-glutamine $\left(400 \mathrm{mgL}^{-1}\right)$ in media influenced continuous treatment up to 4-6 weeks can lead to efficient somatic embryogenesis formation in $P$. sufficient embryogenesis induction and with less guajava. Similarly, several reports confirmed that morphogenic abnormality. Similarly, Moura and formation of direct SEs was enhanced by glutamine Motoike, (2009) reported that 2, 4-D alone cannot (Baskaran and Jayabalan 2009; Deo et al., 2010; induce somatic embryogenesis in guava cv. Paluma. Gerdakaneh et al., 2011). After 4-5 weeks in induction The addition of 2, 4-D (2.0 $\left.\mathrm{mgL}^{-1}\right)$ with L-glutamine medium small clusters of pre-embryogenic mass cells $\left(400 \mathrm{mgL}^{-1}\right)$ significantly increased formation of (PEMC) of cytoplasm rich cells were visible (Fig.1).

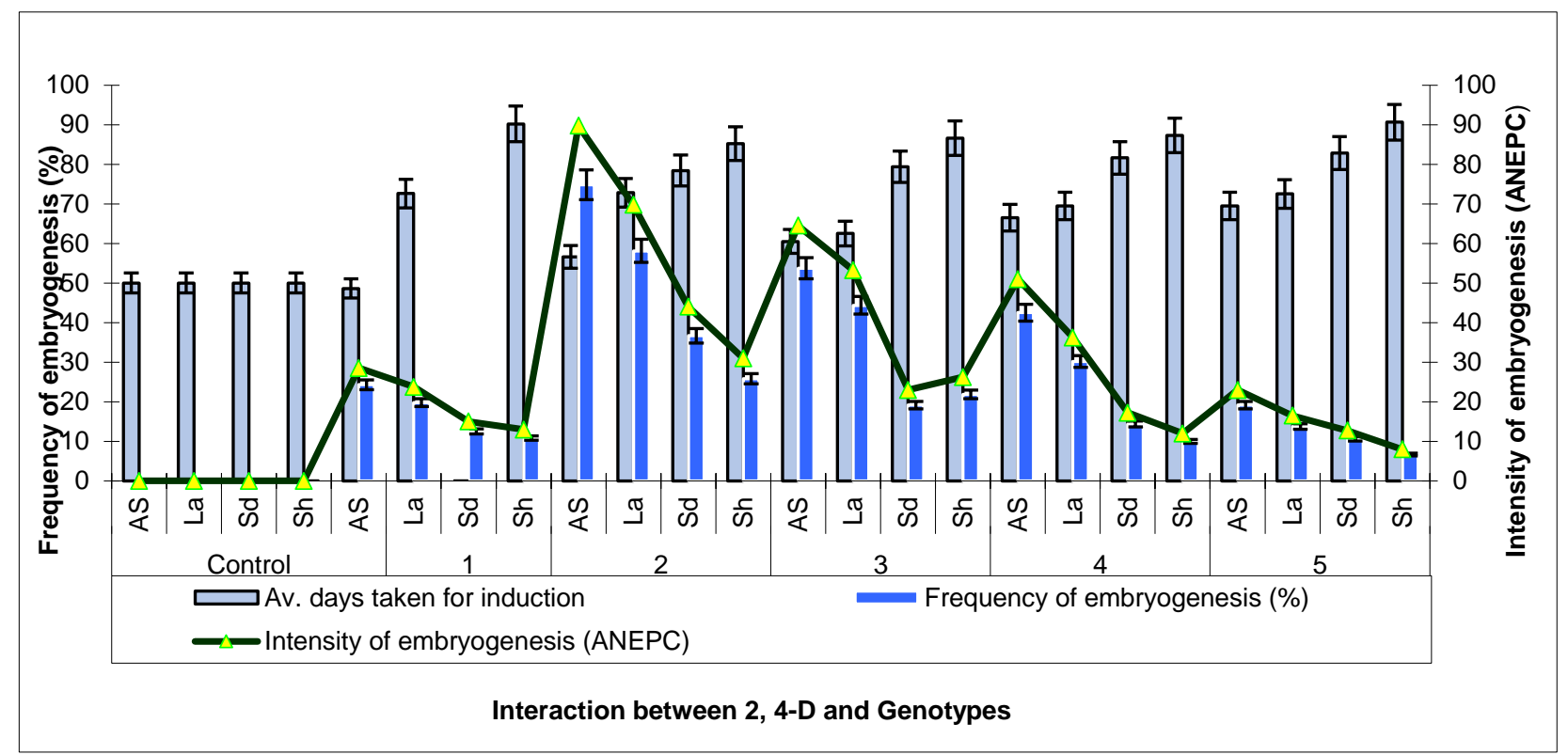

Figure 4 - Effect of 2, 4-D and its interactive effect on the four genotypes of guava. Represents maximum embryogenesis induction in terms of frequency and intensity with reference to the four genotypes

Since direct somatic embryogenesis had often seen in formation of somatic embryos (Lou and Kako, 1995; hypocotyls region in several species including Luo et al., 1996; Nakagawa et al., 2001). Similarly, Myrtaceae, it is likely that PEMC originate from enhanced induction of somatic embryos achieve by hypocotyls region. In vitro growth and development adding high concentration of sucrose to the culture of tissues requires a carbon source because of medium in cucumber (Luo et al., 1996), iris (Jehan et heterotrophic mode of nutrition. Sucrose is the most al., 1994) and melon (Nakagawa et al., 2001). conjoint carbohydrate source used in the plant tissue Previously, 5\% sucrose in guava (Kosky et al., 2005; culture and present dominantly in the phloem Rai et al., 2007) found best for induction of somatic (Zimmerman and Zeigler, 1975). Research claimed embryogenesis. Our results revealed that 6\% sucrose that carbohydrate concentration affects greatly in the found best for inducing maximum embryogenesis in 
guava with less time supports our previous report by Chandra et al. (2004) in mesocarp tissue of guava. However, at lower concentration $(2 \%, 3 \%$, and $4 \%)$ of sucrose not efficiently induce somatic embryogenesis (Rai et al., 2007). High carbohydrate content in culture medium found increased somatic embryogenesis in many plant species (Luo et al., 1996; Rai et. al., 2009). However, it is a common fact that the role of high sucrose concentration in somatic embryogenesis may influence the cell osmolarity (May and Trigiano, 1991). Therefore, the role of sucrose in the present study interpreted as both nutritional and osmotic regulatory functions of the carbohydrate which creates a stress that can lead to embryogenesis induction. Therefore, it is recommended that, osmotic effect of sucrose may cause normal development of somatic embryos. Genotype is the most important factor influencing embryogenic response and SE is highly genotype dependent process. Some genotypes are highly regenerative where as others are recalcitrant especially in case woody tree species. Variability in the induction and frequency of the obtained embryos observed among different species of genera and within the cultivars. Considerable variations in embryogenic capacity observed between individuals of one cultivar or species. Genotype-dependent embryogenic capability was widely reported. In some genotypes, genes involved in plant regeneration may be suppressed due to inappropriate culture medium and culture condition. According to the present findings, we claimed Allahabad Safeda as found best genotype for establishing successful somatic embryogenesis. Individual genotypes may also have unique requirements for optimal regeneration capacity. Such genotypic differences in embryogenic capacity might reflect current differences in the ability to activate key elements in the embryogenic pathway (Merkle et al., 1995).

The use of PEG as an osmoticum in maturation media for somatic embryos has proven effective in increasing germination and conversion (Capuana and Debergh, 1997). Polyethylene glycol reported to improve the quality of somatic embryos by promoting normal differentiation of the embryonic shoot and root (Stasolla et al., 2003). PEG molecules are too large to move through the cell wall and do not cause plasmolysis. Non-plasmolyzing osmotic are more effective in promoting somatic embryo maturation (Linossier et al., 1997; Walker and Parrott, 2001). In our findings conversion of guava somatic embryos into plantlets achieve successfully on 1/2 MS medium fortified with BAP $\left(0.5 \mathrm{mgL}^{-1}\right)$ and NAA $\left(0.2 \mathrm{mgL}^{-1}\right)$, casein hydrolysate $\left(100 \mathrm{mgL}^{-1}\right)$ containing $3 \%$ sucrose results in $52.36 \%$ plantlet regeneration. Similarly, Rai et al. (2009) also reported the use of PEG in guava embryo maturation. Carrier substrate plays a major role in hardening and acclimatization of tissue culture raised plantlets. This is the most critical stage to look after the tissue-cultured plantlets before planting into field as the maximum plants dies during hardening stage. Coco peat as carrier substrates have marked effect on the plant height, number of leaves, number of roots, length of roots, number of shoots/explant and their survival per cent. This indicated that coco peat was effective carrier substrate for acclimatization. Coco peat absorb water and release gradually. It provides sufficient aeration for development of healthy roots. However, in case of guava successful acclimatization of rooted shoots reported in peat-based compost and autoclaved FYM + Sand (1:1) by various workers (Amin and Jaiswal, 1988; Prakash 1992; Prakash and Tiwari, 1993; 1996). Hardened plantlets shifted in field where they are growing vigorously. Mishra et al. (2004) have found that micro propagated plantlets of Bael can be acclimatized under $50 \%$ shade and high relative humidity $(70 \%)$. Our results also corroborated with Mishra et al. (2007) that the survival of rooted plantlets of Psidium guajava L. was high in coco peat substrate. Maximum survival of plants ( $84 \%)$ noticed on autoclaved coconut husk fortified with $1 / 2 \mathrm{MS}$ plant salt mixture. The transfer of tissue culture raised plantlets to field conditions is one of the most critical factors that cause higher production costs. High mortality rate observed when plants transfer to field conditions as cultured plants had non-functional stomata, weak root system and poorly developed cuticle. In order to increase growth and reduce mortality in plantlets at the acclimatization stage, research focused on the control of the environmental conditions (both physical and chemical). Addition of bio agents such as Trichoderma harzianum in the carrier substrate not only enhances survival of the plant but it also augmented development of fibrous root and vigor of the plant. Fortification of $T$. harzianum in coco peat found best results for increasing survival and growth of guava plants. Thus, bio hardening by employing bioagents promote growth and encourage mutual association that the plantlets may oppose upon transplantation to natural conditions (Varma and Schuepp, 1996; Hernandez et al., 1999; Sahay and Varma 1999; Pandey et al., 2000). Bioagents such as Glomus aggregatum, T. harzianum and Piriformospora indica found very effective in improving the establishment frequency. 
Bio hardening is an emerging dimension of tissue culture technique for implementation of successful hardening and acclimatization of plants (Lovato et al., 1996; Nowak, 1998; Sahay and Varma, 1999; Pandey et al., 2000; Rai, 2001; Srivastava et al., 2002).

\section{CONCLUSION}

In this research paper, we established a highly efficient and regenerative protocol for recurrent somatic embryogenesis in guava genotypes Allahabad Safeda. This consistent repetitive embryogenesis system will provide a reliable source for genetic improvement of Psidium guajava L. and can potentially useful in further expansion of genetically modified guava with enhanced aroma, better shelf life, resistance to wilt and seedlessness.

\section{ACKNOWLEDGMENT}

This article is dedicated in the memory of Dr.Ramesh Chandra.

Author (MK) is thankful to Director, Central Institute for Subtropical Horticulture, Lucknow, India for providing necessary research facility. The Author (MK) duly acknowledge Ben Gurion University of the Negev, Israel.

\section{REFERENCES}

1. Akhtar, N. Evaluation of the efficiency of somatic embryogenesis in guava (Psidium guajava L.). J. Hort. Sci. Biotech. 2010; 85: 556-562.

2. Amin, M.N., Jaiswal, V.S. Micropropagation as an aid to rapid cloning of guava cultivars. Sci. Hort., 1988; 36: 89-95

3. Ammirato, P.V.: Embryogenesis. In: Evans, D.A., Sharp, W.R., Ammirato, P.V. and Yamada, Y. (eds.): Handbook of Plant cell Cultures.. Macmillan, New York 1993; Vol. 1: Pp. 82-123.

4. Arnold, S.V., Sabala, I., Bozhkov, P., Dyachok, J., Filonova, L. Developmental pathways of somatic embryogenesis. Plant Cell Tiss Org. Cult. 2002; 69: 233-249.

5. Baskaran, P., Jayabalan N. In vitro propagation of Psoralea corylifolia L. by somatic embryogenesis in cell suspension culture. Acta Physiol Plant. 2009; 31:1119-1127.

6. Biswas, B.K, Yadav, A., Joshee, N.,Yadav, A.K. In vitro plant regeneration and genetic transformation to enhance cold hardiness in guava: A nutraceutical fruit. Acta Hort. 2005; 735: 31-32.

7. Canhoto, J.M., Cruz, G.S. Feijoa sellowiana Berg (Pineapple guava). In: Bajaj, Y.P.S. (ed.):
Biotechnology in Agriculture and Forestry, Trees IV. 1996; Vol. 35: Pp 156-172.

8. Canhoto, J.M., Cruz, G.S. Improvement of somatic embryogenesis in Feijoa sellowiana Berg. (Myrtaceae) by manipulation of culture media composition. In Vitro Cell. Dev. Biol. 1994; 30: 21-25,.

9. Canhoto, J.M., Lopes, M.L., Cruz, G.S. Somatic embryogenesis and plant regeneration in myrtle (Myrtaceae). Plant Cell Tissue Org. Cult. 1999; 57: 13-21.

10. Capuana, M., Debergh, P.C. Improvement of the maturation and germination of horse chestnut somatic embryos. Plant Cell Tissue Organ Cult. 1997; 48: 2329.

11. Carman, J.G., Bishop, D.L. and Hess, J.R. Carbohydrates, minerals and free amino acids in Triticum aestivum L. kernels during early embryony. J. Plant Physiol. 1996; 149: 714-720.

12. Chandra, R., Bajpai, A., Gupta, S., Tiwari, R.K. Embryogenesis and plant regeneration from mesocarp of Psidium guajava L. (guava). Indian J. Biotech. 2004; 3: 246-248.

13. Chandra, R., Kamle, M. and Bajpai, A. 'Guava' In: (Eds. H.P. Singh et al.): Advances in Horticultural Biotechnology vol.1-Regeneration Systems-Perennial fruit crops plants and spices. Westville publishers, New Delhi. 2010; Pp 103-120.

14. Cruz, G.S, Canhoto, J.M. and Abreu, M.A.V. Somatic embryogenesis and plant regeneration from zygotic embryos of Feijoa sellowiana Berg. Plant Sci. 1990; 66: 263-270.

15. Deo, P.C., Taylor, M., Harding, R.M., Tyagi, A.P., Becker, D.K. Initiation of embryogenic cell suspensions of taro (Colocasia esculenta var. esculenta) and plant regeneration. Plant Cell Tissue Organ Cult. 2010; 100: 283-29.

16. Dhir, S.K., Dhir, S., Widholm, J.M. Plantlet regeneration from immature cotyledon protoplasts of soybean (Glycine max L.). Plant Cell Rep. 1991; 10:39-43.

17. Dunstan, D.I., Tautorus, T.E., Thorpe, T.A. Somatic embryogenesis in woody plants. In: Thorpe, T.A. (ed.): In-vitro embryogenesis in plants. Kluwer Academic Publishers, Dordrecht 1995; Pp 471-538.

18. Feher, A., Pasternak, T.P., Dudits, D. Transition of somatic plant cells to an embryogenic state. Plant Cell Tissue Org Cult. 2003; 74: 201-228.

19. Feher, A. Why somatic plant cells start to form embryos? In: Mujib, A., Samaj J. (eds.): Somatic Embryogenesis in Plant Cell Monographs. 2005. Springer-Verlag, Berlin - Heidelberg Vol. 2. Pp. 85101.

20.Feng, D.L., Li, W., Li, J., Li, P.T., Zhao, M., Zhao, S.G., Shi, B.S., Peng, W.X. Observation of somatic embryogenesis and histology in Koelreuteria bipinnata Franch var integrifoliola. Chen. Plant Physiol. Commun. 2009; 45:855-858. 
21. Gerdakaneh, M., Mozafari, A.A., Mardah, A., Sarabi, B. Effects of different amino acids on somatic embryogenesis of strawberry (Fragaria 3 ananassa Duch.). Acta Physiol Plant. 2011; 33:1847-1852.

22. Kamle, M., Kumar, P., Bajpai, A., Kalim, S. and Chandra, R. (2013). Assessment of genetic fidelity of in vitro regenerated guava (Psidium guajava L.) plants using DNA based markers. New Zealand J. Crop Hort. Sci. 42(1)1-9.

23. Khlifi, S., Tremblay, F.M. Maturation of black spruce somatic embryos. Part I. Effect of L-glutamine on the number and germinability of somatic embryos. Plant Cell Tissue Org. Cult. 1995; 41: 23-32.

24. Kosky, G.R., Perozo, J.V., Penalver, D.A. Somatic embryo germination of Psidium guajava L. The Rita ${ }^{\circledR}$ temporary immersion system and on semisolid medium. - In: Kosky, G.R., Perozo, J.V. and Penalver, D.A. (eds.): Liquid Culture System in in vitro micropropagation. 2005. Springer Verlag, Heidelberg, Germany Vol. 1. Pp-225-229.

25. Leljak-Levanic, D., Bauer, N., Mihaeljavic, S., Jelaska, S. Changes in DNA methylation during somatic embryogenesis in Cucurbita pepo L. Plant Cell Reports. 2004; 23: 120-127.

26. Linossier, L., Veisseire, P., Cailloux, F., Coudret, A. Effects of abscisic acid and high concentrations of PEG on Hevea brasiliensis somatic embryos development. Plant Sci. 1997; 124: 183-191.

27. Litz, R.E., Gray, D.J. Somatic embryogenesis for agricultural improvement. World J. Microbio. Biotech. 1995; 11: 416- 425.

28. Lovato, P.E., Gianinazzi, P.V., Trouvelot, A., Gianinazzi, S. The state of mycorrhizas and micropropagation. Adv. Hort. Sci. 1996; 10: 46-52.

29. Luo, H., Obara-Okeyo, P. Tamaki, M. and Kako, S. Influence of sucrose concentration on in vitro morphogenesis in cultured cucumber cotyledons explants. J. Hort. Sci. 1996; 71: 497-502.

30. Menzel, C.M. Guava: An exotic fruit with potential in Queensland. Queensland Agri. J. 1985; 111: 93-98.

31. Merkle, S.A., Parrott, W.A., Flinn, B.S. Morphogenic aspects of somatic embryogenesis. In: Thorpe TA (Ed). In vitro embryogenesis in plants. 1995. Dordrecht, Kluwer Academic Pp 155-203.

32. Mishra, M., Chandra, R., Pati, R. and Bajpai, A. Micropropagation of Guava (Psidium guajava L.) Acta Hort. 2007; 735: 153-157.

33. Moura, E.F., Motoike, S.Y. Induction of somatic embryogenesis in immature seeds of guava tree cv. Paluma. Rev. Bras. Frutic. Jaboticabal. 2009; 31: $507-$ 511.

34. Muralidharan, E.M., Gupta, P.K., Mascarenhas, A.F. Plantlet production through high frequency somatic embryogenesis in long-term cultures of Eucalyptus citriodora. Plant Cell Rep.1989; 8: 41-43.

35. Murashige, T., Skoog, F. A revised medium for rapid growth and bioassays with tobacco tissue cultures. Physiol Plant. 1962; 15: 473-497.

36. Nowak, J. Benefits of in vitro 'biotiziation' of tissue cultures with microbial inoculants. In Vitro Cell Dev. Biol. Plant. 1998; 34: 122- 130.

37. Pandey, A., Palni, L.M.S., Beg, N. Biological hardening of tissue culture raised tea plants through rhizosphere bacteria. Biotechnol. Lett. 2000; 22: 10871091.

38. Prakash, H. Micropropagation of guava (Psidium guajava) Ph.D. Thesis. GBPUAT, Pantnagar, India 1992.

39. Prakash, H., Tiwari, J.P. 1996. In vitro clonal propagation of guava (Psidium guajava L.) cv. Sardar. National Symposium on Horticulture Biotech. Indian Institute of Horticultural Research, Bangalore, 28-30 pp.4.

40. Prakash, H., Tiwari, J.P. 1993. Micropropagation of Guava (Psidium guajava). International Conference on Biotechnology in Agriculture and Forestry, New Delhi Pp 1-2.

41. Raemakers, C.J.J.M., Jacobsen, E., Visser, R.G.F. Secondary somatic embryogenesis and applications in plant breeding. Euphytica, 1995; 81: 93-107.

42. Rai, M.K. Current advances in mycorrhization in micropropagation. In Vitro Cell Dev. Biol. Plant. 2001; 37: 158-167.

43. Rai, M.K., Akhtar, N. and Jaiswal, V.S. Somatic embryogenesis and plant regeneration in Psidium guajava L. cv. Banarasi local. Sci. Hort., 2007; 113:129-133.

44. Rai, M. K., V.S. Jaiswal and Jaiswal, V.S. (). Effect of selected amino acids and polyethylene glycol on maturation and germination of somatic embryos of guava (Psidium guajava L.). Sci. Hort. 2009; 121:233236.

45. Robichaud, R.L., Veronica, C.L., Merkle, S.A. Treatments affecting maturation and germination of American chestnut somatic embryos. J. Plant Physiol. 2004; 161: 957-969.

46. Sahay, N.S., Varma, A. Piriformospora indica: a new biological hardening tool for micropropagated plants. FEMS Microbiol. Lett. 1999; 181: 297-302.

47. Saw, L.G., Lafrenkie, J.V., Kochumenn, K.M., Yap, S.K. Fruit trees in a Malaysian rain forest. Eco. Bot. 1991; 45:120-136.

48. Schmidt, E.D.L., Guzzo, F., Toonen, M.A.J., DeVries, S.C. A leucine-rich repeat containing receptor-like kinase marks somatic plant cells competent to form embryos. Development. 1997; 124: 2049-2062. 
49. Sharp, W.R., Sondahl, M.R., Caldas, L.S., Maraffa, S.B. The physiology of in vitro asexual embryogenesis. Hort. Rev. 1980; 2: 268-310.

50. Singh, G. High density planting in guava- application of canopy architecture. ICAR News (April-June), 11: 9-10, 2005

51. Song, Y. Insight into the mode of action of 2, 4dichlorophenoxyacetic acid (2, 4-D) as an herbicide. $J$. Integr. Plant Biol. 2013; 56:106-113.

52. Srivastava, P.S., Bharti, N., Pande, D., Srivastava, S. Role of mycorrhiza in in vitro micropropation of plants In: Mukerji, K.G., Manoharachari, C., Chamola, B.P. (Eds.) Techniques in Mycorrhizal Studies. 2002. Kluwer Academic Publishers, Netherland Pp. 443-460.

53. Srivastava, S., Chawla, H.S. Synergistic effect of growth regulators and glutamine on regeneration response in high yielding cultivars of wheat (Triticum aestivum L.). Indian J Genet. 2001; 61:12-15.

54. Stasolla, C., Van-Zyl, L., Egertsdotter, U., Craig, D., Liu, W., Sederoff, R.R. The effects of polyethylene glycol on gene expression of developing white spruce somatic embryos. Plant Physiol. 2003; 131: 49-60.

55. Van Winkle, S.C., Johnson, S., Pullman, G.S. The impact of gel rite and activated carbon on the elemental composition of two conifer embryogenic tissue initiation media. Plant Cell Rep. 2003; 21:1175-1182.

56. Varma, A., Schuepp, H. Influence of mycorrhization on growth of micropropagated plants. In: Mukerji, K.G. (Ed.) Concepts in Mycorrhizal Research, 1996.Kluwer Academic Publishers. London Pp. 13132. guajava L. starting at the zygotic embryo stage. Rev. Fac. Agron. (LUZ). 2002; 19: 284-293.

58. Walker, D.R., Parrott, W.A. Effect of polyethylene glycol and sugar alcohols on soybean somatic embryo germination and conversion. Plant Cell Tissue Org. Cult. 2001; 64: 55-62.

59. Watt, M.P., Blakeway, F., Creswell, C.F., Herman, B. Somatic embryogenesis in Eucalyptus grandis. Sth. Afr. For. J. 1991; 157: 59- 65.

60. Wilson, C.W. Guava. In: Tropical and sub-tropical fruits: Composition, properties, and uses. Nagy, S., Shaw, P.E. (Eds.): 1980. AVI, Westport, CT Pp-279299.

61. Yadava, U.L. Physicochemical properties of guava produced in Georgia. Hort. Sci. 1994; 29: 536-537.

62. Yang, X., Zhang, X. Regulation of somatic embryogenesis in higher plants. Crit Rev Plant Sci. 2010; 29: 36-57.

63. Zimmerman, J.L. Somatic embryogenesis: a model for early development in higher plants. The Plant Cell. 1993; 5: 1411-1423.

64.Zimmermann, M.H., Ziegler, H. List of sugars and sugar alcohols in sieve-tube exudates. InZimmermann, M.H. and Milburn, J.A. (Eds.): Encyclopedia of Plant Physiology. 1975. Springer Verlag, Berlin-Heidelberg, New York, Vol.1: Pp480 503

65. Zouine, J., El Hadrami, I. Effect of 2, 4-D, glutamine and BAP on embryogenic suspension culture of date palm (phoenix dactylifera L.). Sci. Hort. 2007; 112: 221-226. 